\title{
UMA INSTITUIÇÃO DE ENSINO POPULAR NO MARANHÃO IMPÉRIO: A SOCIEDADE ONZE DE AGOSTO
}

\author{
Samuel Luis Velázquez Castellanos \\ Cesar Augusto Castro
}

UFMA

\begin{abstract}
RESUMO
Propõe-se a análise da contribuição da "Sociedade Onze de Agosto", procurando entendêla como centro de referência cultural no solo maranhense do século XIX. Esta instituição tinha a finalidade de oferecer a instrução das primeiras letras à população adulta, com privilégio aos conteúdos das artes mecânicas e industriais. Descreve-se o movimento social, político e educacional do oitocentos, de modo a situar as condições que propiciaram a criação do estabelecimento em 1870. Considera-se o ensino noturno oferecido aos trabalhadores em diferentes localidades da Província, como Caxias, Alcântara e São Bento, por exemplo. Enfatiza-se a Escola Normal criada pela "Sociedade Onze de Agosto", que objetiva formar professores e professoras para o ensino primário, para o ensino das artes voltadas às atividades manuais (carpinteiro, sapateiro, alfaiate, etc.) e para a indústria, o comércio e a lavoura.

Palavras-chave: Sociedade Onze de Agosto; Maranhão Império; Escola Normal; Educação de Adultos
\end{abstract}

\section{AN INSTITUTION OF POPULAR EDUCATION IN MARANHÃO EMPIRE: THE "SOCIEDADE ONZE DE AGOSTO"}

\begin{abstract}
It is proposed the analysis of the contribution of the "Sociedade Onze de Agosto" trying to understand it as cultural reference center in Maranhão of nineteenth century. This institution was intended to offer education of the first letters to the adult population, with the privilege of mechanical and industrial arts content. It is described the social, political and educational movement of 1800 s in order to situate the conditions that provided to the creation of the institution in 1870. It is considered the night courses offered to workers in different localities of the province, as Caxias, Alcântara and São Bento, for example. It is emphasized the Normal School created by "Sociedade Onze de Agosto", which aims to train teachers for primary education, for the teaching of arts related to manual activities (carpenter, shoemaker, tailor, etc.) and industry, trade and the crop.

Keywords: "Sociedade Onze de Agosto". Maranhão Empire. Normal School. Adult Education
\end{abstract}

\section{Introdução}

Neste trabalho ao tomar-se como parâmetro de análise as iniciativas privadas no cenário educacional oitocentista no Maranhão, tratamos de discorrer sobre as peculiaridades da Sociedade Onze de Agosto $^{1}$ fundamentando-nos em três eixos essenciais: o seu papel como instituição formadora, sua influência na instrução e educação do povo 
timbira e de que forma tratou de se estabelecer como centro de referencia cultural no solo maranhense do século XIX, se levamos em consideração que a sua criação em São Luis, em 1870, tinha como finalidade, o oferecimento da instrução das primeiras letras e saberes à população operária e adulta, preferencialmente, abrangendo os conteúdos direcionados às artes mecânicas e industriais.

Estas tentativas instrucionais e organizações educativas fazem parte de um movimento maior que gira em torno da organização e expansão do campo educacional na Província que se inicia em 1827 e amplia-se nas décadas de 30 e 40, com a fundação do Liceu (1837), no qual se tinha preferência pelo atendimento das classes abastada que almejavam a realização do ensino superior nas Faculdades de Olinda, Recife, Rio de Janeiro e São Paulo ou em países da Europa, notadamente Portugal e França. A Casa dos Educandos Artífices (1841), em contraposição à educação elitizada, volta-se para o ensino do ler, escrever e contar da parcela pobre e desvalida da província, visando à formação profissional: ensinamentos sobre os ofícios de carpinteiro, alfaiate, marceneiro, dentre outras ocupações que o Maranhão carecia. $\mathrm{O}$ aumento na numerabilidade de colégios no espaço educacional maranhense constitui exemplos do crescimento de escolas particulares, nesse período. A criação do Colégio de Santana; do Colégio Episcopal de Nossa Senhora dos Remédios (em 1840); o de Nossa Senhora da Glória (para meninas) ou Colégio Abranches (em 1844); do Asilo de Santa Teresa (em 1855); do Colégio de Nossa Senhora de Nazareth (em 1864), do Instituto de Humanidades; do Internato e Externato de São Paulo e do Colégio de São Caetano, demonstram como influenciou a Lei da Instrução Pública de 1827. Segundo Castellanos (2010, p. 121), o Maranhão "[...] aumentara o número de escolas de 14 para 24 num curto período de tempo, representando um passo na difusão da educação por parte da Província" e assumindo destaque na instrução de meninos e meninas; entretanto, a classe operária adulta não tinha sido até então objeto de atenção instrucional por parte de iniciativas governamentais, nem por particulares.

Essa expansão das oportunidades de ensino no Maranhão oitocentista - pública e particular- deveu-se sobremaneira pelo franco desenvolvimento econômico advindo da produção e exportação de produtos agrícolas, como o algodão, o arroz e o açúcar, propiciando à capital da província transformações urbanas tais como o calçamento das ruas, a iluminação pública, o embelezamento das praças e avenidas, a criação do teatro, a biblioteca pública provincial, o gabinete português de leitura, as diferentes associações entre outros espaços de sociabilidades que fez de São Luís, uma das mais prospera e belas cidades do Império, como retratam viajantes estrangeiros que por aqui estiveram (CALDEIRA, 1998).

A imprensa, antes restrita a poucos jornais que circulavam pelas ruas e ladeiras de São Luis (diária ou semanalmente) cresce de forma significativa diante de todo esse processo de civilidade e progresso, o que pode evidenciar o exercício das práticas leitoras e a ampliação do nível de escolaridade da população, inclusive das camadas mais pobres e desvalidas da província. Esse crescimento da cidade e da oferta de produtos e serviços anunciados nos jornais revela o crescimento do consumo de produtos importados, desde os livros e outras materialidades culturais, até o que de mais atual e moderno havia na arte do bem comer, beber e vestir na Europa.

Esse crescimento paulatino no plano econômico e social, assim como as variadas tentativas na melhoria do cenário educacional contribuem para a criação de varias sociedades e/ou associações que se tinham como finalidade a garantia e apoio das atividades profissionais como se pode observar nas sociedades beneficentes dos Ourives (que além de defender os interesses dos seus membros, ofereciam o ensino das primeiras letras e das artes inerente a sua atividade), também se estabelecem essas associações, para 
debater o que havia de mais moderno no campo da ciência e das idéias filosóficas e literárias, como aconteceu com a Sociedade Filomática, a qual oferecia "cursos elementares de ciência" e promovia conferencias públicas em torno de temas centrados no campo das ciências físicas e matemáticas. É nesse movimento de formação das sociedades que é criada a Sociedade Onze de Agosto, que diferente das demais não tinha interesse em oferecer cursos a um grupo especifico de profissional, mas a todas as pessoas da classe operária que almejavam uma instrução baseada nas primeiras letras e nos conhecimentos necessários ao exercício de atividades na indústria, no comercio e na lavoura.

Portanto, neste fazer histórico, tratamos de analisar o processo de criação dessa instituição, tendo como foco de reflexão a obra $O$ Ensino Público de Antonio de Almeida Oliveira, publicada em 1870. Obra que ao ter como autor o idealizador da Sociedade Onze de Agosto, muitas das idéias e princípios educacionais concebidos, discutidos e efetivados em dito espaço escolar permanecem descritos explicitamente nas suas páginas, em especial, quando se trata do ensino não convencional ministrado no período noturno a uma parcela da classe trabalhadora, assim como os fundamentos norteadores do papel dessa instituição na formação para o magistério por meio da criação da Escola Normal como segunda tentativa maranhense de institucionalização da formação pedagógica. Tentativa esta que se apresenta após 30 anos de se constituir uma aula de Pedagogia baseada no método Lancaster oficialmente recomendada pela Instrução Pública para todo o país ${ }^{2}$ (localizada numa sala do Convento do Carmo) onde também funcionava o Liceu Maranhense (CASTELLANOS, 2010). Investida que pretende consolidar a Escola Normal maranhense após de 39 anos de constituída a primeira Escola Normal brasileira. Tentativa na qual não se obteve o resultado esperado ${ }^{3}$. Desta forma, procura-se compreender neste trabalho, em principio, o lugar que a Sociedade Onze de Agosto ocupou na Província do Maranhão oitocentista e as suas diversas atuações no cenário educacional e cultural.

\section{O Ensino noturno no Maranhão}

O ensino noturno no Maranhão surgiu, em 1868, pela iniciativa do Professor Cruz na Cidade de São Bento, que segundo Olivieira (2003, p.180) foi essa a primeira escola nessa modalidade funcionando em Brasil. A partir de 1870, pela lei N. 920 de julho que estabelece o novo regulamento para a instrução pública na Província, se converte o Liceu em internato, tornando-se o ensino obrigatório e criando-se as aulas noturnas em Caxias, Alcântara, Viana e Itapecuru-mirim.

O professor particular que se dedicar a este nobre trabalho, receberá uma gratificação marcada pelo presidente da Província e sujeita à aprovação da Assembléia. Se for público, o professor terá mais metade do seu ordenado, logo que apresente vinte discípulos pelo menos, recebendo desde já esta gratificação o professor público da Vila de São Bento, se continuar a sustentar a aula noturna, que foi o primeiro a estabelecer na Província (LEI, 1870, Apud. CASTRO, 2009, p. 221).

Essa iniciativa de José da Silva Maia, presidente da Província de criar aulas noturnas em vários locais vinha ao encontro da necessidade de instruir jovens e adultos que durante o dia não dispunham de tempo para aprender a ler, escrever e contar. Para Oliveira (2003, p.178), as leis que obrigavam o adulto a trabalhar poderiam obrigá-lo a aprender, por que uma coisa era tão moralizadora como a outra "[...] sem instrução nenhum trabalho pode ser profícuo". Por isso, achava conveniente que essa modalidade de ensino deveria 
ser aberta a ambos os sexos, mas com o necessário rigor de fiscalização e com professores e professoras com bons exemplos de "respeito e decência, homens e mulheres aprenderão juntamente sem faltar os deveres da mais severa moralidade" (OLIVEIRA, 2003, p.178). Para este autor, o ensino a noite deveria ser estendido também às instituições carcerárias para garantir a educação dos presos e dos soldados, se fazia “" [...] preciso, pois, aumentar-se o número de escolas do exército, estabelecer-se o ensino em todas as prisões e criar-se uma escola pelo menos em cada município para os ignorantes adultos que não estiverem no caso dos soldados e dos presos" (OLIVEIRA, 2003, p.177).

Oliveira entendia, ainda que:

A instrução não e uma necessidade só da infância e para a infância. O homem aprende quando menino para utilizar-se dos seus conhecimentos quando adulto. Adulto mesmo a necessidade da instrução é cotidiana. A vida inteira é um aprendizado de todas as horas e tão imperioso que a instrução da infância fica incompleta, e tende a minguar para quem a ele se submete (2003, p.179).

Essa tipologia escolar, para este autor, deveria ser denominada de Escolas Populares por se voltarem totalmente para a educação gratuita de todas as esferas da sociedade, constituindo-se esta a diferença marcante entre os princípios da educação monárquica e a republicana, "estes deixando ao povo o poder de governar-se, dando-lhes na instrução o meio de saber de donde parte e para onde vai. Aqueles repousando em princípios contrários sempre se [mostrando] amigos das trevas" (OLIVEIRA, 2003, p. 33). Idéias expostas e discutidas na obra $O$ ensino Publico (primeira obra brasileira imprensa que tratou as questões pedagógicas com profundidade, segundo Barbosa de Godóis), que vão orientar as políticas educacionais da Sociedade Onze de Agosto, na medida em que o autor como um dos seus membros principais, expõe com veemência nos seus escritos, uma ampla e consistente defesa da escola pública e popular, da liberdade de ensino e da formação docentes entre muitas outras temáticas, que fizeram desta obra, uma referência importante quando se quer discutir a educação brasileira nos oitocentos, sendo colocadas em prática muitas dessas déias concebidas e discutidas, na tentativa de consolidar essa instituição.

A criação da Sociedade Onze de Agosto foi uma iniciativa de vários intelectuais maranhenses, dentre eles, Antonio de Almeida Oliveira ${ }^{4}$ e João Antonio Coqueiro $^{5}$, os quais receberam apoio de Martiniano Mendes Pereira e de Manoel Jansen Pereira "[...] cavalheiros de nossa sociedade [que] correspondendo ao apelo daqueles dignos cidadãos, e inspirados no mesmo interesse, não regatearam auxílios, concorrendo com donativos, alguns de bem alto valor, merecendo serem agraciados pelo governo imperial com títulos nobiliários e condecorações" (REVISTA ELEGANTE, 1898, p.2)

Almeida Oliveira, formado em Direito pela Faculdade de Recife, teve uma importante participação na política maranhense ao fundar o primeiro jornal dedicado a defender os princípios republicanos, $O$ Democrata e, ao inaugurar no Maranhão uma "espécie de universidade popular em conferências públicas, sendo também o criador com [...] Eneas de Sousa, da Biblioteca Popular" (Marques, 2008, p.81). Antonio Coqueiro, doutor em Ciências Físicas e Matemáticas pela Universidade de Bruxelas e bacharel em Ciências pela Faculdade de Ciências de Paris, foi um dos fundadores do Jornal da Lavoura e autor de várias obras didáticas entre as quais o famoso Tratado de Aritmética e Curso Elementar de matemática. "O livro Tratado de Aritmética de João Antonio Coqueiro, foi escrito quando o mesmo tinha apenas 18 anos de idade. Teve grande aceitação tanto no 
Brasil como em Portugal. O livro recebeu elogios dos matemáticos da época P. Renoux e L. Tarbouriech, sendo até hoje considerada uma das melhores de seu gênero" (SOARES, 2009, p. 114).

Em matéria que circulou no jornal o Publicador Maranhense, de 17 de agosto de 1870, informa que a Onze de Agosto foi instalada dois dias antes da data do artigo, nos Salões da Escola Normal, onde estiveram presentes mais de cem pessoas "sem distinção de classe ou cor política" que ouviram entusiasmadas os discursos dos seus fundadores. Na oportunidade, Francisco Peixoto Franco de Sá e Manoel Jansen Pereira, ofereceram-se para ministrar à noite as aulas de desenho linear aplicado às artes e de mecânica industrial, respectivamente. Essas disciplinas evidenciam o direcionamento dos conteúdos escolares para o exercício das atividades profissionais. Similares disciplinas, foram ministradas na Casa dos Educandos Artífices e na Escola Agrícola do Cutim, portanto se evidencia que a instrução proposta na Onze de Agosto, vinha ao encontro de uma série de investimentos realizados por particulares e pelo governo provincial em formar mão-de-obra para atender às necessidades do comércio e

da indústria local.

Apesar do teor elogiativo do artigo dado aos idealizadores pela criação da Escola Popular Onze de Agosto se fazia um alerta sobre o entusiasmo iniciático das propostas educacionais no cenário maranhense, mostrando não só a importância da sua criação, como também a necessidade de se tomarem medidas para sua permanência, ao dizer que:

Assim, pois, a idéia que a Sociedade Onze de Agosto pretende levar a efeito é simpática ao nosso povo, é de reconhecida utilidade para ele; muito, porém, vai do modo de realizá-la. É preciso notar de mais que esse mesmo povo que acolhe as boas idéias com pronta benevolência se acha como que descrente das empresas que se tem querido realizar entre nós em vista do seu nenhum resultado (PUBLICADOR MARANHENSE, 1870, p. 3).

A descrença da população com iniciativas dessa natureza dava-se pelo curto ciclo de vida da maioria das instituições sociais, culturais e educacionais saoluicenses implantadas nos oitocentos, a exemplo do Teatro União (1817-1848), do Asilo de Santa Tereza (1855-1870), da Escola Agricola do Cutim (1854-1863). Para que a Onze de Agosto não seguisse esse mesmo caminho incerto e se consolidasse como espaço escolar de ensino gratuito e popular visando à instrução das camadas menos favorecidas, se precisava ter parcimônia nos investimentos e nas suas pretensões como lugar de referencia educacional e cultural maranhense, indicando o Publicador Maranhense, por meio de um artigo jornalístico, algumas sugestões, alegando que deveríamos supor:

[...] que a Sociedade Onze de Agosto é uma linda menina que acaba de nascer; sobrecarregá-la de enfeites quando a gentileza consiste em harmonia e sob disposição das formas; arroxear-lhe os pulsos com pesados braceletes; fazer perder-lhe do delicado pescoço um colar em feição de dourada, e dos tenros dedinhos grossos anéis, é por certo querer sufocá-la debaixo desses ricos adornos, e antes que os membros adquiram a força precisa para sustentá-los. Assim começar com ostentação esta Sociedade é matá-la antes de produzir os benefícios resultados que dela se espera; é dar-lhe iguarias assaz pesadas para o estômago que por ora só pode suportar ligeiros alimentos. Somos de opinião que a Sociedade Onze de Agosto deve ter principalmente em vista cortar todas as despesas 
desnecessárias e dispensáveis; não receio que se fine à míngua de alimentos, não. Podem, é verdade, se estes parcos, mas de boa qualidade; cuide-se de tomar a medidas para que no futuro possa dar grandes resultados, e para os quais, sim, a parcimônia é condenável, assim é que tendo de instituir-se cursos noturnos e sendo de grande e extraordinária importância os de química e física que não podem ser feito sem os competentes aparelhos, aplica-se todas as economias que se puder fazer em mandá-los buscar na Europa, e uma vez nesta Capital, a primeira talvez do Norte que os tenha de possuir, só por si darão avultada importância à nossa bela instituição (PUBLICADOR MARANHENSE, 1870, p.3).

Sob a presença de autoridades locais e do presidente da Província Augusto Olympio Machado, no dia 27 de setembro foi eleita a direção da instituição, ficando assim constituída: Presidente: Dr. Antonio de Almeida Oliveira; Vice-Presidente: Roberto H. Hall; 1 Secretário: João Antonio Coqueiro; 2 Secretário: Martiniano Mendes Pereira; Tesoureiro: João José Fernandes Silva; Procurador: Theodoro José da S. Bessa e Bibliotecário: Manoel Jansen Pereira. No dia 2 de dezembro, às 5 da tarde foram abertas, "numa festa patriótica e literária, à que assistiram, além dos sócios, grande número de pessoas de todas as classes" (FEREIRA, 1933, p. 11), as aulas de primeiras letras, que nas palavras do presidente da instituição "possam elas viver vida prospera e longa que isso será o galardão do fraco concurso que tenho prestado" (FEREIRA, 1933, p.12).

Assim, todas as noites, os 150 alunos, distribuídos em trinta por classe tinham aulas de ler, de escrever e de contar com o professor Raymundo Joaquim Serra e Eusébio Victoriano Cavalcante de Barros (adjunto); de gramática portuguesa com Antônio Telles de Bêrredo; de aritmética, álgebra e geometria com o professor Cândido Jorge Sonher Barbosa e de construção prática e desenho com professor Agostinho Autran. Aos domingos, pela manhã recebiam aulas de desenho e a noite Almeida Oliveira fazia prelações de assuntos morais e sociais ${ }^{6}$. As aulas de química, física e mecânica não puderam, nesse ano, ser iniciadas por falta de laboratórios e aparelhos e do espaço acanhado do prédio. A escola foi instalada numa das casas à Rua dos Afogados desta cidade, mas sem acomodações precisas, tendo em breve de suspender as aulas que já funcionavam regularmente.

"Os infatigáveis empreendedores de tão alevantado cometimento cada vez mais fortalecidos na ideia patriótica e útil que os prendia, resolveram comprar ou edificar um prédio adequado ao fim" (REVISTA ELEGANTE, 1898, p. 2). Com o crescente aumento da frequencia às aulas, a diretoria com o apoio da presidência da província, tratou de cogitar os meios precisos para obter um prédio com vastas proporções. A respeito do assunto se manifesta Gomes de Castro (MARANHÃO. Relatório..., 1871, p. 24).

Em quase todas as províncias do Império se tem construído casas para escolas por meio de donativos particulares. E esta é a melhor prova de quanto é simpática a idéia de derramar a instrução nas classes menos favorecidas. Não podia o Maranhão ser indiferente a tão grandioso pensamento e de forte apelo que a esse respeito dirigir aos meus concidadãos vai encontrando o mais lisonjeiro acolhimento. Desejando levantar em nesta cidade um edifico modesto, mas cômodo, onde pudessem funcionar as aulas da sociedade 11 de agosto e outras quaisquer que no futuro se abrirem e ao mesmo tempo estabelecer uma biblioteca popular e um museu de história natural da província. Dirigi circulares solicitando donativos para tal útil empresa. 
Os donativos arrecadados viabilizaram a compra de um prédio amplo e situado na Rua do Egito $^{7}$ e sob a responsabilidade do engenheiro/arquiteto Agostinho Autran reformas, mudanças e adaptações foram realizadas. No salão principal, no andar superior, destinado às conferências públicas e aos atos solenes todo o espaço foi decorado e preparado por um artista espanhol e pelos alunos da Casa de Educandos Artífices sob a supervisão de Domingos Tribuzzi. Na sua abobada em pintura fina destacavam-se vários medalhões, simetricamente dispostos, contendo figuras representativas da arte, da lavoura, da indústria e do comércio e "No alto das paredes desse mesmo salão, artisticamente inscritos, liam-se, em belos relevos, os nomes dos maiores vultos da antiguidade, e dos que tornaram o Maranhão a Athenas no Brasil" (FERREIRA, 1933,p.15). Segundo a Revista Elegante (1898, p. 2) "o todo do edifício [era] elegante, e segundo opiniões de competentes, construído não só com muita solidez como subordinado às exigências da arte". Figuras importantes das letras foram representadas no alto em frente ao edifício, tais como: Gonçalves Dias ${ }^{8}$, Sotero dos Reis ${ }^{9}$, Gomes de Sousa ${ }^{10}$, o General Falção ${ }^{11}$, João Lisboa $^{12}$, como se pode observar na figura abaixo:

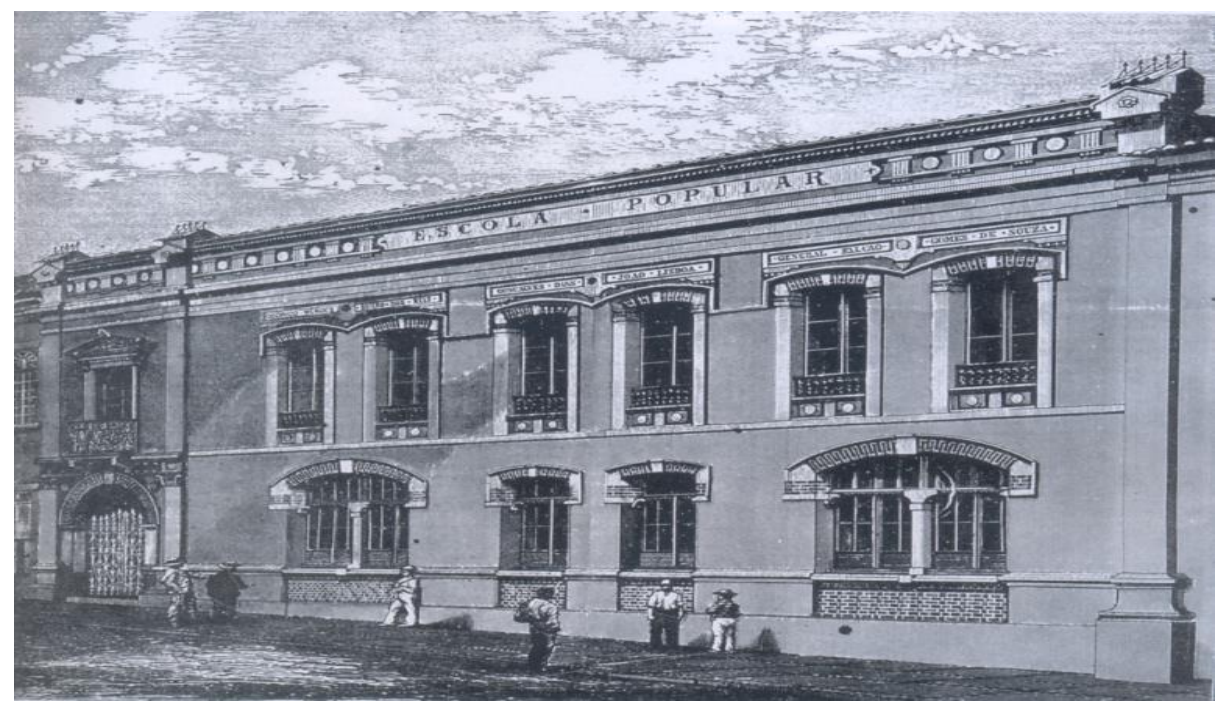

Fonte: Foto publicada no Jornal O Novo Mundo, New York, v.5, n.53, 22 fev. 1875.

Em pouco tempo, “[...] ficou construído um novo edificio que não deixou a desejar, reabrindo-se as aulas dos diferentes cursos já iniciados, sendo aprovados outros. $\mathrm{O}$ ensino era feito sem remuneração para a classe laboriosa occupada em outros misters" (REVISTA ELEGANTE, 1898, p. 2), prometendo-se à população o mais habil e idoneo professorado, integrado e vigilante pela nova causa educacional. Seu secretário, Martiniano Mendes Perreira, por meio da imprensa, controlava as matriculas, anunciando as vagas para as "Aulas do Curso Noturno e da Escola Normal; [avisando que é] por isso que termina[vam] hoje as férias de que trata o art. 2 do regulamento interno" (PUBLICADOR MARANHENSE, 1875, p. 3), assim como, publicavam-se demonstrativos com as seguintes aulas e o respectivo número de matriculados mostrando assim o funcionamento da instituição, "[...]matriculados em primeira letra (29); em gramática (12); em aritmética (6), em geometria (8) e em desenho (18)" (PUBLICADOR MARANHENSE, 1871, p.2).

Práticas similares aconteciam em outras instituições e com a própria inspetoria da instrução, a qual orientava em 1852, ao Secretario da Instrução Pública, João Isidoro Xavier de Brito, a descrever e a publicar na imprensa, as horas de entrada e de saída das 
aulas no Liceu Maranhense e a "[...] informar aos pais as faltas de seus filhos" (O PUBLICADOR MARANHENSE, 1852, p. 4), como também, ao Secretario da Instrução Pública, em 1871, Mariano Cesar de Miranda Leda "[...] a transcrever a relação nominal dos alunos que durante o mês de agosto findo, faltaram às respectivas aulas de inglês, francês, latim, geografia, matemática, filosofia, historia, gramática e retórica" (O PUBLICADOR MARANHENSE, 1871, p. 1). Estratégias de imposição escolares que denunciam o funcionamento das instituições educativas e o controle destes espaços educacionais sobre os indivíduos e as táticas de apropriação dos sujeitos em lugares controláveis, que disseminavam suas formas de fazer e de ser.

O apoio financeiro do governo na compra e reforma do prédio, na aquisição de matérias escolares e na organização e procura dos mobiliários, fez com que este se achasse no direito de interferir nas atividades da Escola do Povo Onze de Agosto e, principalmente na ocupação de seu espaço por outras instituições, trazendo problemas a seu funcionamento e desenvolvimento. A Biblioteca Pública Provincial (que passa a ser denominada de Biblioteca Popular) ao ocupar o salão nobre do prédio, termina inviabilizando a continuidade das conferências pedagógicas e as aulas de desenho que nele aconteciam, atingindo nesse período a sua fase de maior florescimento, segundo Castro e Silva (2009). Mas foi a proposta da Assembléia Provincial em 1876 de transferir o Liceu para o prédio da Onze de Agosto a que causou maior repercussão social e posição contraria da sua diretoria, trazendo consigo múltiplos determinantes que incidiram negativamente no funcionamento do prédio no sentido

geral e na sustentação desta Escola Popular no plano particular. Na opinião de Ferreira $(1933$,

p. 30).

Em vez de determinar a mudança do Liceu para o prédio onde funcionava o Colégio da Imaculada Conceição, espaçoso, contendo salas grandes, claras e

bem ventiladas e suficientes para os misteres do Liceu, preferiu a Assembléia Legislativa Provincial perturbar a existência da Sociedade 11 de Agosto e prejudicar os cursos que ali mantinham, sem que houvesse vantagem para o ensino, visto que o Liceu ficaria mal colocado, pois apesar de seu um prédio bem acabado, de conter no andar superior um excelente salão, tinha estreitas dimensões ao bom funcionamento desse instituto de ensino, que exigia salas para aulas, salas de espera dos alunos, sala da congregação para a Inspetoria e Secretaria, devendo ainda acomodar a repartição de Instrução Pública.

Tendo a sociedade Onze de Agosto deixado de funcionar e estando o prédio arruinado, o Dr. Jose Manoel de Freitas, então Presidente da província, dando execução ao art. 11 da Lei n. 1155 de 5 de setembro de 1876 mandou que fosse indenizado os credores da dita sociedade passando o referido prédio a ser próprio provincial. Em 1877, o prédio passa alojar a Sociedade Maranhense Protetora dos alunos pobres da província que recebiam roupas, calçados e material didático para puderem frequentar as aulas públicas de primeiras letras. Neste prédio se montou a biblioteca Publica e se restabeleceu a aula noturna, “[...] nomeando para administrá-la o professor Raimundo Joaquim Cezar, tendo inicio desde $1^{\circ}$ de Agosto de 1882 com uma freqüência media de cem alunos, constante de operários das fundições, aprendizes de alfaiate, marceneiro, sapateiro" (REVISTA ELEGANTE, 1898, p. 3). 
Em 1884, por determinação dos deputados e do presidente da província a Assembléia Legislativa Provincial que ocupava uma das salas do Convento do Carmo e celebrava suas sessões no consistório da Catedral, cedido pelos Bispos da Diocese, resolveu por falta de cômodo e espaço necessário a sua transferência para o edifício mencionado, onde continuou tendo para esse fim efetuado alguns reparos indispensáveis. A transferência da Assembléia para a Sociedade Onze de Agosto acaba desestabilizando totalmente suas atividades, principalmente o funcionamento da biblioteca pública que volta para sua primeira sede (Convento do Carmo), a qual havia sido ocupada até então, pelo poder legislativo, "A Província, entrando em plena posse deste edifício, pagaria as dividas da Sociedade, montaria, restaurando no salão onde já se achavam os livros e material indispensável, a Biblioteca Provincial, e, no pavimento térreo, sustentaria a aula noturna de ensino primário" (FERREIRA, 1833p. 23), que se transfere posteriormente para a residência do professor Horácio Bello quando da instalação no seu espaço da Repartição de Higiene (1886). "Hoje funciona ali no pavimento superior o Congresso Estadual e no pavimento térreo a Repartição de Higiene e a Escola Pública do $1^{\circ}$. Distrito" (REVISTA ELEGANTE, 1898, p. 3).

Acabou-se assim a existência tão útil da Sociedade 11 de Agosto. Todavia,

as energias ali dispensadas, semelhante ao que se passa nos domínios da mecânica, não se consumirem, senão se transformaram, não somente construindo cidadãos instruídos que abraçaram varias profissões em que denotaram a cultura de nossa terra, mas ainda legando este edifício que, perpetuando a memória dessa Sociedade, forma um patrimônio do ensino, nesta Capital, vastamente conhecida por Escola Noturna, Escola do Povo, Escola Popular 11 de Agosto (FERREIRA, 1933, p.24).

\section{A Escola Normal noturna da Sociedade Onze de Agosto}

Em 1874 por meio da lei 1088 de 19 de junho no governo de José Francisco de Viveiros, vice-presidente da Província do Maranhão, é criada a Escola Normal noturna da Sociedade com o com o fim de formar professores para o ensino primário. Quando da sua criação existiam no Brasil, 113 escolas normais, sendo 83 públicas e 53 particulares nas quais estavam matriculados 5.720 alunos todos do sexo masculino, como demonstra o quadro abaixo.

Quadro I: Mapa das escolas noturnas para adultos que existiam no Brasil

\begin{tabular}{|c|c|c|c|c|c|c|c|c|c|c|c|c|}
\hline \multirow{4}{*}{ Províncias } & \multicolumn{6}{|c|}{ Públicos } & \multicolumn{6}{|c|}{ Particulares } \\
\hline & \multirow{2}{*}{\multicolumn{3}{|c|}{$\begin{array}{l}\text { Aulas } \\
\text { Sexos }\end{array}$}} & \multirow{2}{*}{\multicolumn{3}{|c|}{$\begin{array}{c}\text { Alunos } \\
\text { Sexos }\end{array}$}} & \multirow{2}{*}{\multicolumn{3}{|c|}{$\begin{array}{l}\text { Aulas } \\
\text { Sexos }\end{array}$}} & \multirow{2}{*}{\multicolumn{3}{|c|}{$\begin{array}{c}\text { Alunos } \\
\text { Sexos }\end{array}$}} \\
\hline & & & & & & & & & & & & \\
\hline & Masc & Fem. & Total & Masc. & Fem. & Total & Masc & Fem & Total & Masc & Fem & Total \\
\hline Amazonas & 2 & & 2 & 102 & & 102 & 1 & & 1 & 75 & & 75 \\
\hline Pará & 7 & & 7 & 98 & & 98 & 5 & & 5 & 268 & & 268 \\
\hline Maranhão & & & & & & & 6 & & 6 & 495 & & 495 \\
\hline Piauí & 6 & & 6 & 142 & & 142 & & & & & & \\
\hline Ceará & $1^{13}$ & & 1 & & & & & & & & & \\
\hline $\begin{array}{l}\text { Rio Grande do } \\
\text { Norte }\end{array}$ & 1 & & 1 & 66 & & 66 & 3 & & 3 & 130 & & 130 \\
\hline Paraíba & 1 & & 1 & 79 & & 79 & & & & & & \\
\hline Pernambuco & $13^{14}$ & & 13 & 377 & & 377 & 5 & & 5 & 121 & & 121 \\
\hline Alagoas & 9 & & 9 & 236 & & 236 & & & & & & \\
\hline
\end{tabular}




\begin{tabular}{|c|c|c|c|c|c|c|c|c|c|c|c|c|}
\hline Sergipe & 1 & & 1 & 67 & & 67 & 3 & & 3 & 69 & & 69 \\
\hline Bahia & $15^{15}$ & & 15 & 547 & & 547 & 11 & & 11 & 312 & & 312 \\
\hline Espírito Santo & 2 & & 2 & 41 & & 41 & 1 & & 1 & 13 & & 13 \\
\hline Rio de janeiro & $19^{16}$ & & 19 & & & & 6 & & 6 & & & \\
\hline $\begin{array}{c}\text { Município } \\
\text { Neutro }\end{array}$ & 3 & & 3 & 199 & & 199 & 6 & & 6 & 1896 & & 1896 \\
\hline Santa Catarina & & & & & & & & & & & & \\
\hline São Pedro & & & & & & & 2 & & 2 & 131 & & 131 \\
\hline São Paulo & 3 & & 3 & 121 & & 121 & 1 & & 1 & 29 & & 29 \\
\hline Minas Gerais & $* 17$ & & $*$ & & & & & & & & & \\
\hline Parana & 1 & & 1 & 38 & & 38 & 1 & & 1 & 22 & & 22 \\
\hline Mato Grosso & & & & & & & & & & & & \\
\hline Goias & & & & & & & 2 & & 2 & 47 & & 47 \\
\hline Soma & 83 & & & 2.113 & & 2.113 & 53 & & 53 & 3.607 & & 3.607 \\
\hline
\end{tabular}

Fonte: Oliveira, 2003 (anexo 5)

Por esta tabela fica evidente o predomínio de escolas normais particulares, em termos quantitativos, como também o número de alunos matriculados. A grande incidência de escolas particulares no Maranhão Império, principalmente as de ensino das primeiras letras e do ensino secundário, foi objeto de constante reclamação dos Presidentes de Província e dos Inspetores Escolares que julgavam conveniente uma maior fiscalização sobre essas instituições e que era dever da Província manter e estimular a criação de escolas públicas de instrução primária e secundária por acreditarem que estas poderiam oferecer um estudo de maior e melhor qualidade, principalmente, para as crianças e jovens oriundas das famílias pobres do Maranhão. (MARANHÃO, Relatório..., 1870).

A Escola Normal da Sociedade Onze de Agosto foi autorizada pela Lei n. 1088 de 17 de julho de 1874, como segunda tentativa de se estabelecer o ensino normalista de caráter privado no cenário ludovicense, tendo como fim educacional a administração de uma série de cursos pedagógicos, o ensino teórico e prático indispensável às pessoas que se destinavam ao magistério da instrução primária com duração de 2 anos, as quais deveriam ser avaliadas em disciplinas de ensino secundário e em uma de formação pedagógica, expressas na seguinte composição curricular.

Primeiro ano: $1^{\mathrm{a}}$ cadeira-curso de gramática e língua portuguesa; $2^{\mathrm{a}}$ cadeiraCurso de aritmética teórica aplicada aos problemas usuais da vida - e de geometria prática com aplicação agrimensura, nivelamento e levantamento de plantas; $3^{\mathrm{a}}$ cadeira-Curso moral, doutrina cristã e pedagogia ${ }^{18} ; 4^{a}$ cadeira-Curso elementar de geografia, física e cosmografia e a aula de Desenho linear aplicado às artes. Segundo ano: $1^{\mathrm{a}}$ CadeiraContinuação do curso de gramática; $2^{a}$ Cadeira-Curso elementar de História Santa, da idade média e moderna; $3^{a}$ Cadeira-Curso de noções de física, química, história natural acompanhada de alguns conhecimentos relativos à indústria e às máquinas e higiene; $4^{\mathrm{a}}$ Cadeira-Curso de rudimentos de direito natural público e de economia política e a aula de Desenho linear e lavis applicados às artes (REGULAMENTO, 1871 apud CASTRO, 2009).

Cadeiras e aulas que eram ministradas pelos mais prestigiados e competentes professores maranhenses no período como Joaquim Teixeira de Souza, Manoel Jansen Pereira e Antonio Jansen de Mattos Pereira, dentre outros que:

Gratuitamente ali ensinavam, não só preparavam os candidatos ao professorado primário, os quais, posteriormente, prestavam concurso ante o Conselho de Instrução, mas ainda os alunos que se candidatavam aos 
exames gerais de preparatórios, a que, sob a fiscalização de um Delegado, designado pelo Inspetor da Instrução Pública da Côrte, se procedia nas províncias. Tais exames geralmente se realização no Liceu, mas, algumas vezes, na escola 11 de agosto (FERREIRA, 1933,p.16-17).

O ensino ministrado no curso normal objetivava formar um professor que além do domínio dos conhecimentos requeridos para o exercício da profissão docente pudesse ensinar disciplinas relacionadas à formação de artífices (CASTELLANOS, 2010). Desse modo, é possível afirmarmos que o ensino normal proposto, além de preparar o professor para ensinar os alunos a ler, a escrever e a contar inserido nos princípios morais e religiosos, também eram preparados para o ensino das artes da indústria, do comércio e da lavoura. Essas disciplinas não diferem na denominação e no conteúdo das ministradas na Casa dos Educandos Artífices, como o desenho, a geometria e a aritmética aplicada às artes. Nesse tipo de ensino, o professor seria na escola como o "motor no centro de uma fábrica ou de um engenho. Como faltando o motor o engenho ou a fábrica fica sem movimento; faltando mestre, a escola não pode trabalhar" (OLIVEIRA, 2003, p. 203).

As formas de organização curricular e as concepções de ensino, de formação para o magistério primário adotado na Escola Normal pode ser compreendida, a partir de Almeida Oliveira (2003), na Obra O Ensino Público, na quarta parte em que trata do Magistério. $\mathrm{O}$ autor defende que assim como em outras profissões - médicos e advogados - o professor deveria ter uma "capacitação superior" a ser oferecida pelas Escolas Normais, por ser ela "[...] uma fonte de estudos teóricos e práticos. Ao mesmo tempo em que se ministra o ensino experimenta o gosto do aluno, desenvolve-lhe a vocação e a forma-lhe o caráter nos predicados, que devem coroar o exercício da pedagogia" (OLIVEIRA, 2003, p. 213). Essas escolas deferiam ser assentadas nas seguintes bases: primeiro deveriam ser mistas para atender a ambos os sexos, por igualdade de benefícios da instrução e pela economia nas despesas. Segundo, não deveriam ser internatos para que os alunos pudessem ter lições da experiência e a prática do mundo. Terceiro, as aulas deveriam ser regidas por homens e mulheres, entretanto, a direção deveria ser restrita ao sexo masculino, por faltar na mulher a "energia e a gravidade pedida pelo emprego, os trabalhos devem exigir uma atividade se não impossível extremamente difícil para o sexo fraco" (OLIVEIRA, p.215). Quarto, ao lado de cada escola deveria funcionar uma escola municipal de primeiras letras para que os alunos desenvolvessem as atividades práticas.

Como auxiliar na formação do professores deveria ser realizado as conferências pedagógicas que deveriam ser proferidas por pessoas da sociedade, mas principalmente pelos alunos de modo a expressarem suas idéias e o avanço do aprendizado adquirido na sala de aula e nas vivencias práticas.

Na visão de Oliveira (2003 p. 220)

As conferências dos professores são, pois, para as questões da escola o que é o parlamento para as altas questões do Estado. Tendo todos, a faculdade de apresentar e defender teses concernentes ao ensino, cada um pode comunicar aos outros não só as idéias que têm, e as dificuldades que encontra na carreira, como os métodos e as práticas que emprega no ensino e o bom e o mau êxito que coroa os seus esforços. Tendo cada um o direito de falar sobre os assuntos dados para ordem do dia, podem todos correr com suas luzes para que a verdade seja descoberta e o erro confundido. 
Para este autor, o professor ou a professora formado pelas Escolas Normais deveriam ser pessoas virtuosas e dotada de qualidades extraordinárias, mas seria o sexo feminino o ideal para a instrução primária por terem paciência e a bondade que as crianças precisam para o seu desenvolvimento. Por isso, defende que as mulheres não afeminavam os meninos e nem a sua presença em sala de aula criava o desrespeito entre os alunos e destes com a professora. O professor deveria ser:

Puro nos costumes, no dever exato

Modesto, polido, cheio de bondade,

Paciente, pio, firme no caráter,

Zeloso, ativo e tão prudente

Em punir como em louvou;

Agente sem ambições, apostolo

Em que a infância se modela,

Espelho em que os mundos se refletem,

Mito e sociedade, juiz e pai,

Eis o mestre, eis o professor (OLIVEIRA, 2003, p.204).

Para isso, o professor deveria ser bem remunerado para que não abandonasse o magistério por carreiras mais rentáveis e prestigiadas, sendo uma das prerrogativas para que alcançasse respeito e credibilidade, participar do movimento docente em agremiações. Além de reproduzir o conhecimento em sala de aula, deveria ser obrigado a escrever uma das obras (compêndios ou livros) sobre qualquer das matérias do ensino.

Essa obra deve ser oferecida ao conselho central da instrução no ato de pedir o professorado à declaração da vitaliciedade, a fim de por ela se julgar das suas habilitações. Se a obra for declarada má, ou no fim dos cinco anos o professor tiver contra si qualquer fato que ponha em dúvida a sua moralidade, a declaração da vitaliciedade poderá ser retardada, no primeiro, caso até a apresentação de nova obra, no segundo até que finde o termo da espera proposta pelo conselho e aprovada pelo governo (Oliveira, 2003, p. 225).

As ideais de Oliveira (2003) foram se efetivando quando dirigiu a Sociedade Onze de Agosto e a Escola Normal, já que por meio das conferências pedagógicas e do ensino mutuo, em que mesmo em número reduzido, a presença das mulheres matriculadas na escola se mostrou crescente, principalmente, nos anos de 1880 e teve certa autonomia em relação às injunções do governo na administração da escola, apesar da injeção permanente de recursos pelos cofres provinciais.

As aulas na Escola Normal eram realizadas em duas etapas: a primeira teórica, onde o aluno aprendia o que havia de mais atual em termos de métodos de ensino e, em seguida, aplicavam os seus conhecimentos na escola de primeiras letras para crianças e adultos existentes na instituição. Aulas que eram ministradas todos os dias, das seis e meia às 8 horas da manhã e pela tarde, das 5 às 9 horas da noite (com os cursos de aritmética, geometria, moral e história) para utilidade dos alunos da instrução primária com duração de uma hora e meia. As aulas de desenho, sendo a exceção, duravam duas horas e seriam ministradas duas vezes por semana, inclusive os domingos, em duas seções para os alunos de um e outro sexo que se destinavam ao magistério primário.

Os professores e substitutos seriam nomeados e admitidos pela diretoria da Sociedade que teriam a seu cargo o programa das aulas aprovadas pelo governo que deveriam ser ministradas com clareza e com a "pausa necessária para que os alunos 
possam apanhar, resumindo a parte substancial da prelação nos Cadernos" (REGULAMENTO, 1871 apud CASTRO, 2009, p.437) e em seguida seriam submetidos à argüição com a finalidade de verificar se eles cumpriram ou não as obrigações que lhes eram impostas, apresentado assim um relatório mensal à diretoria da Escola contendo a declaração dos pontos obtidos pelos docentes com suas respectivas condutas.

Ao término dos dois anos de duração do curso o diploma com a assinatura do Presidente da Província, do diretor da instituição, do inspetor da instrução pública, do secretário da Sociedade, dos professores e dos examinadores presentes nos exames, os graus de aprovação, que obtinha em cada um dos anos, o no exame geral, e que o júri o considerava habilitado para o exercício do magistério público. Em seguida, o diploma era entregue em sessão solene pelo diretor perante a congregação, recebendo o aluno na mesma ocasião um anel, segundo o modo estabelecido pela congregação.

\section{Conclusão}

Apesar da importância que a Sociedade 11 de Agosto assume na educação maranhense como espaço de formação educacional e cultural, lugar de destaque de lutas ideológicas, políticas, sociais e educacionais, caracterizando-se por se constituir uma topografia implícita de coordenadas teóricas, choques metodológicos e embates metódicos, e recebendo na sua trajetória educativa e escolarizante, a nomenclatura de Escola Popular, Escola do Povo ou Escola Noturna, as injunções econômicas e, especificamente, as conjunturas políticas, não impediram que a mesma sofresse no decorrer do seu ciclo de vida uma série de mudanças que lentamente foram impedindo o seu desenvolvimento e descaracterizando a sua finalidade: a de instruir crianças e adultos de ambos os sexos nas primeiras letras e, a de criar uma Escola Normal Noturna, para suprir a carência de professores com formação para atuarem na instrução primária. Além disso, "com a criação da Escola Normal, muitos dos sócios protetores deixaram de cumprir o seu papel, entre os sócios efetivos, uns têm sonegado e outros têm deixado de pagar as suas anuidades por causa da subvenção que a Província dá para manutenção das aulas do dito curso" (ARQUIVO PÚBLICO, 1878).

Todos estes fatores têm contribuído com o término da Escola Normal e das aulas de primeiras letras de crianças, jovens e adultos que iam "ali a encontrar o pão do espírito, para que [pudessem] no futuro ser úteis a si, aos seus e à pátria. O mesmo se dá com os adultos que [procuravam] com o trabalho divino do ler e do escrever, seus meios de subsistência. Destes personagens há muitos exemplos, pois é geralmente sabido que para ali tem entrado homens maiores de quarenta anos completamente analfabetos que hoje sabem ler, escrever e contar (manuscrito, ano).

O fim da Sociedade 11 de Agosto termina reproduzindo a história parcial de quase todas as histórias das instituições maranhenses criadas no período imperial, ou seja, a maioria das instituições (educacionais ou não) no cenário ludovicense do século XIX que trazem em sua história, uma vida atribulada por falta de recursos, constantes embates políticos partidistas e interesses econômicos contrapostos, uma trajetória incerta pelos descasos das autoridades com o bem público, com a educação, a cultura e os espaços de sociabilidade e um descaso da sociedade elitista maranhense na sua generalidade, preocupada com a individualidade em detrimento do bem comum, como profetizava a imprensa periódica no artigo escrito pelo Publicador Maranhense citado neste texto.

\section{Referências}


ARQUIVO PÚBLICO DO ESTADO DO MARANHÃO. Sociedade Onze de Agosto. Cx1 (setor de manuscritos).

CALDEIRA, Jorge. Leitura dos viajantes no Maranhão no século XIX. EDUFMA, 1998.

CASTELlanOS, Samuel Luis V. Práticas leitoras no Maranhão na Primeira República: entre apropriações e representações. São Luis: EDUFMA, 2010.

CASTRO, Cesar Augusto; SILVA, Diana Rocha. Em busca do tempo perdido: a direção de Antonio Lobo e a consolidação da Biblioteca Pública no cenário ludovicense-1898-1910. 18 p. mimeo.

CASTRO, Cesar Augusto. Leis e regulamentos da instrução pública no Maranhão Império: (1835-1889). São Luis: EDUFMA, 2009.

FERREIRA, Justo Jansen. A Escola 11 de agosto. São Luis: IHGE/MA, 1933.

MARANHÃO. Relatório que sua excelência o senhor vice-presidente da província, Jose da Silva Maia, apresentou no dia 18 de maio de 1870 perante a Assembléia Legislativa Provincial, por ocasião da instalação de sua sessão ordinária. São Luis, Tip. De J.M.A. Serrão, 1870.

MARANHÃO. Relatório lido pelo excelentíssimo senhor presidente, dr. A. O. Gomes de Castro, por ocasião da instalação da Assembléia Legislativa desta província no dia 3 de maio de 1871. São Luis, Tipografia B. de Matos, 1871.

MARQUES, Cesar Augusto. Dicionário Histórico-Geográfico da Província do Maranhão. 3.ed. ver. e ampl. São Luis: Edições AML, 2008.

OLIVEIRA, A. de Almeida. O ensino público. Brasília: Senado Federal, 2003.

PUBLICADOR MARANHENSE, São Luis, 1870.

REVISTA ELEGANTE, São Luis, 1898.

SOARES, Waléria de Barros. Juros em livros didáticos no Maranhão no século XIX. Dissertação ( Programa de Pós-graduação em Matemática) - Universidade Estadual de Campinas, 2009.

\footnotetext{
${ }^{1}$ Nome escolhido para comemorar a data de criação dos Cursos Jurídicos no Brasil

${ }^{2}$ Lei da Instrução Pública promulgada em 15 de novembro de 1827 . Tinha como finalidade suprir a falta de professores e difundir o ensino primário, ao promover os alunos mais adiantados para auxiliarem os mais atrasados.

${ }^{3}$ Ver Castellanos (2010).
} 


\footnotetext{
${ }^{4}$ Nasceu na Cidade de Codó em 17 de outubro de 1843. Escreveu várias obras com destaque para O Ensino Público, onde defende uma educação popular e republicana. Deputado Geral pelo Maranhão, Ministro da Marinha (1883) e Presidente da Província de Santa Catarina.

${ }^{5}$ Nasceu em 1837 dedicou-se ao ensino da matemática sendo professor da Sociedade Onze de Agosto, da Casa dos Educandos Artífices e do Liceu Maranhense. Diretor do Colégio Pedro II e do Externato do Ginásio Nacional.
}

${ }^{6}$ Ministraram também disciplinas: Joaquim Teixeira de Souza (Gramática Nacional); Manoel Jansen Pereira (Aritmética, Desenho e Construção); Dr. Joao Antonio Coqueiro (Geometria aplicada as Artes); A. Jansen de Mattos Pereira (História Geral). Revista Elegante (1898, p. 2).

${ }^{7}$ Este prédio pertencia ao Desembargador Francisco Xavier Coutinho

${ }^{8}$ Poeta maranhense de maior expressão

${ }^{9}$ Primeiro diretor do Liceu Maranhense e Inspetor da Instrução Pública. Autor de vários livros didáticos com destaque para a Gramática Portuguesa, adotada em várias escolas brasileiras.

${ }^{10}$ Matemático.

${ }^{11}$ Primeiro diretor da Casa dos Educandos Artífices. Durante a sua administração (1841- 186?) a instituição foi reformada, regulamentada e muito das suas atividades de ensino foi empreendida por José Antonio Falção.

${ }^{12} \mathrm{Um}$ dos mais importantes e expressivos jornalistas maranhenses

${ }^{13}$ Ceará - Diz-se o Sr. João Brígido que se criaram três escolas para adultos em 1871, mas, que tendo sido provida só uma; essa mesma foi depois extinta por falta de frequentadores.

${ }^{14}$ Pernambuco - compreende-se a escola dos mecânicos liberais.

${ }^{15}$ Bahia - Como se trata de escolas para adultos, compreendo aqui uma existente na cadeia, não obstante ser de diurna.

${ }^{16}$ Rio de Janeiro - Ignora-se o número dos alunos, que das escolas públicas quer das particulares.

${ }^{17}$ Minas Gerais - Não tive informações a respeito

${ }^{18}$ Disciplina de formação pedagógica dividida em duas partes: uma metodológica e outra correspondente à didática.

Recebido: abr/15 Aprovado: jun/15 